\title{
Service data analytics and business intelligence 2017
}

\author{
Desheng Dash Wu ${ }^{1,2} \cdot$ Wolfgang Karl Härdle $3,4,5,6$
}

Published online: 11 February 2020

() Springer-Verlag GmbH Germany, part of Springer Nature 2020

\section{Introduction}

With growing economic globalization, the modern service sector is in great need of business intelligence for data analytics and computational statistics. The joint application of big data analytics, computational statistics and business intelligence has great potential to make the engineering of advanced service systems more efficient. The purpose of this computational statistics (COST) special issue is to publish highquality research papers (including reviews) that address the challenges of service data analytics with business intelligence in the face of uncertainty and risk. High quality contributions that are not yet published or that are not under review by other journals or peer-reviewed conferences have been collected. The resulting topic oriented special issue includes research on business intelligence and computational statistics, data-driven financial engineering, service data analytics and algorithms for optimizing the business engineering. It also covers implementation issues of managing the service process, computational statistics for risk analysis and novel theoretical and computational models, data mining algorithms for risk management related business applications.

$凶$ Desheng Dash Wu dash@risklab.ca

$凶$ Wolfgang Karl Härdle haerdle@hu-berlin.de

1 Economics and Management School, University of Chinese Academy of Sciences, Beijing, China

2 Stockholm University, Stockholm, Sweden

3 Blockchain Research Centre, School of Business and Economics, Humboldt-Universität zu Berlin, Unter den Linden 6, 10099 Berlin, Germany

4 Sim Kee Boon Institute for Financial Economics, Singapore Management University, 81 Victoria Street, Singapore 188065, Singapore

5 Department of Probability and Mathematical Statistics, Faculty of Mathematics and Physics, Charles University, Prague, Czech Republic

6 Department of Information Management and Finance, National Chiao Tung University, Xinzhu, Taiwan 
Service data analytics and business intelligence have become an important topic in today's complex, interrelated global environment, replete with threats from larger amounts of aspects, such as natural (Kiremidjian et al. 2007), political (Akhtaruzzaman et al. 2017; Busse and Hefeker 2007), economic (Corbett and de Groote 2000; Jin et al. 2014; Wu et al. 2019; Yu et al. 2008), energy (Wen et al. 2019; Xiao et al. 2018), and technical sources (He et al. 2016; Pan et al. 2019). Data analytics about business intelligence can provide various reality-based examples or projects to examine the economical evaluation and risk assessment, which not only expands literature of service data analytics but also facilitates industry-academy combination. There are still many challenges in service data analytics and business intelligence fields. We therefore also solicited several submissions from (1) 2017 IEEE Symposium on Analytics and Risk held on July 7-9, 2017, in Beijing, China, which attracted more than 100 researchers and scientists from China, USA, Canada, Hong Kong, Italy, UK etc, and (2) 2017 Innovation and Analytics conference on October 17-18, 2017, held in Hainan, China, which attracted about 80 researchers and scientists from China, Germany, Canada, Hong Kong, etc. Both events are from the conference series annually organized by the Center for Environmental Economics, University of Chinese Academy of Sciences and by Analytics and Risk Technical Committee, IEEE Systems Council and Social and Economic Security Technical Committee, IEEE Systems, Man, and Cybernetics Society; and sponsored by the National Natural Science Foundation of China. Professor Desheng Wu and Professor James Lambert chaired the first event while Professor Desheng Wu, Professor Qiang Guo, and Professor Wolfgang Karl Härdle chaired the second event.

\section{This issue}

This special issue contains five accepted research papers. These papers focus on recent advances on topics of service data analytics and business intelligence including the risk analytics in shadow banking systems, queuing problem in hospitals, the distressed companies' prediction, real data analytics in the manufacturing industry, and the dynamic behavior of short-term interest rates analytics.

The work by Chen et al. (2020) analyzes the development of shadow banking systems in China and catalyzes the expansion of banks' off-balance-sheet activities. The paper incorporates banks' overall risk, endogenously into bank's production process as undesirable by-product for the estimation of banks' total factor efficiency (TFE) as well as TFE of each production factor. The results show that, compared with a model incorporated with banks' overall risk, a model considering on-balance-sheet lending activities only may over-estimate the overall average TFE and under-estimate TFE volatility as a whole. Higher overall risk taking of banks tends to decrease bank TFE through a 'diverting effect'. However, significant heterogeneities of bank integrated TFE (TFIE) and TFE of each production factor exist among banks of different types or located in different regions, as a result of still prominent unbalanced development of Chinese commercial banks today. Based on newly estimated TFIE, the paper also investigates the determinants of bank efficiency, and finds that a model with 
risk-weighted assets as undesirable outputs can better capture the impact of shadow banking involvement.

The work by Fan et al. (2020) attempts to compare the performance between a single-stage appointment scheduling system and a two-stage appointment scheduling system. A queuing model is firstly formulated with the objective of maximizing the weighted hospitals benefit minus the cost of patient waiting and doctor overtime, for a two-stage appointment scheduling system considering no-shows in this paper. The performances of two-stage appointment scheduling systems varying with noshow probabilities and probabilities that patients have a second-stage diagnosis are presented. Experimental results indicate that the optimal number of patients needs to be more than the capacity of doctors in the first few slots, and less than those in the last few slots. The results show that under a higher no-show probability, arranging more patients than the workload reduces the waste of doctors capacity; and on the contrary, under a higher probability of doing examinations, arranging fewer patients than the workload can reduce system congestion.

The work by Guan et al. (2020) predicts the distressed companies by a factorial discriminant model based on interval data. Interval data makes both average and volatility information comprehensively included in the proposed prediction model, which is expected to improve prediction performance on the distressed companies. A comparison based on a real data case from China's stock market is conducted. The results show that the $i$-score model is more accurate and more reliable in identification of companies in high risk of financial distress in advance of 2 years.

The work by Kong et al. (2020) addresses the production optimization and/or management problem in the manufacturing industry with real data analytics. The main motivation of this paper is to explore methods for analyzing and evaluating big data with domain knowledge. For this purpose, real production data from a semiconductor manufacturing workshop are adopted as the data object. Besides, this paper proposes quantitative calculation methods of data value density to determine the extent to which data quality can be improved by the proposed data processing techniques. The work in this paper has the potential to be further extended and applied to other big data applications beyond the manufacturing industry.

The work by Yan et al. (2020) proposes a semiparametric time-dependent jump diffusion model in an effort to capture the dynamic behavior of short-term interest rates. The newly proposed model includes a wide variety of well-known interest rate models, incorporating the time-varying instantaneous return, volatility as well as jump component. The local likelihood density estimation technique together with pseudo likelihood estimation method is employed to estimate the parameters of the model. Some simulations are conducted to examine the statistical performance in the paper. The proposed procedure is then applied to analyze daily federal funds rates.

We would like to extend our appreciation to all the authors who have submitted their impressive works for this special issue. We also thank all the reviewers for their service and commitment to this journal. It is crucial to analyze the application of engineering risk with the fast development of various engineering projects. This special issue involves various risk analytics models as well as applications, which could provide advanced perspectives to the existing literature. 
Acknowledgements We sincerely thank Juergen Symanzik (Past Editor-in-Chief) for providing us guidance and support in completing this special issue. This work was supported in part by the Ministry of Science and Technology of China under Grant 2016YFC0503606, in part by the National Natural Science Foundation of China under Grant 71825007, in part by the Chinese Academy of Sciences Frontier Scientific Research Key Project under Grant QYZDB-SSW-SYS021, in part by the Marianne and Marcus Wallenberg Foundation under Grant MMW 2015.0007, in part by the Strategic Priority Research Program of CAS under Grant XDA23020203 and supported by the International Partnership Program of Chinese Academy of Sciences, Grant No. 211211KYSB20180042. Wolfgang K. Härdle thanks the supports from Deutsche Forschungsgesellschaft through the International Research Training Group 1792 "High Dimensional Nonstationary Time Series”, Czech Science Foundation (19-28231X) and the Taiwan YuShan Scholarship.

\section{References}

Akhtaruzzaman M, Berg N, Hajzler C (2017) Expropriation risk and FDI in developing countries: does return of capital dominate return on capital? Eur J Polit Econ 49:84-107. https://doi.org/10.1016/j. ejpoleco.2017.01.001

Busse M, Hefeker C (2007) Political risk, institutions and foreign direct investment. Eur J Polit Econ 23:397-415. https://doi.org/10.1016/j.ejpoleco.2006.02.003

Chen S, Härdle WK, Wang L (2020) Estimation and determinants of Chinese banks' total factor efficiency: a new vision based on unbalanced development of Chinese banks and their overall risk. Comput Stat. https://doi.org/10.1007/s00180-019-00951-6

Corbett CJ, de Groote X (2000) A supplier's optimal quantity discount policy under asymmetric information. Manag Sci 46:444-450. https://doi.org/10.1287/mnsc.46.3.444.12065

Fan X, Tang J, Yan C (2020) Appointment scheduling optimization with two stages diagnosis for clinic outpatient. Comput Stat. https://doi.org/10.1007/s00180-019-00876-0

Guan R, Wang H, Zheng H (2020) Improving accuracy of financial distress prediction by considering volatility: an interval-data-based discriminant model. Comput Stat. https://doi.org/10.1007/s00180019-00916-9

He Z, Cheng TCE, Dong J, Wang S (2016) Evolutionary location and pricing strategies for service merchants in competitive O2O markets. Eur J Oper Res 254:595-609. https://doi.org/10.1016/j.ejor.2016.03.030

Jin Y, Ryan JK, Yund W (2014) Sourcing decisions with competitive suppliers and imperfect information. Decis Sci 45:229-254. https://doi.org/10.1111/deci.12069

Kiremidjian A, Moore J, Fan YY, Yazlali O, Basoz N, Williams M (2007) Seismic risk assessment of transportation network systems. J Earthq Eng 11:371-382. https://doi.org/10.1080/13632460701285277

Kong W, Qiao F, Wu Q (2020) Real-manufacturing-oriented big data analysis and data value evaluation with domain knowledge. Comput Stat. https://doi.org/10.1007/s00180-019-00919-6

Pan Y, Wu D, Luo C, Dolgui A (2019) User activity measurement in rating-based online-to-offline (O2O) service recommendation. Inf Sci 479:180-196. https://doi.org/10.1016/j.ins.2018.11.009

Wen F, Zhao Y, Zhang M, Hu C (2019) Forecasting realized volatility of crude oil futures with equity market uncertainty. Appl Econ 51:6411-6427. https://doi.org/10.1080/00036846.2019.1619023

Wu D, Zhang B, Baron O (2019) A trade credit model with asymmetric competing retailers. Prod Oper Manag 28:206-231. https://doi.org/10.1111/poms.12882

Xiao J, Zhou M, Wen F, Wen F (2018) Asymmetric impacts of oil price uncertainty on Chinese stock returns under different market conditions: evidence from oil volatility index. Energy Econ 74:777-786. https:// doi.org/10.1016/j.eneco.2018.07.026

Yan T, Zhao Y, Wang W (2020) Likelihood-based estimation of a semiparametric time-dependent jump diffusion model of the short-term interest rate. Comput Stat. https://doi.org/10.1007/s00180-019-008751

Yu L, Wang S, Lai KK (2008) Forecasting crude oil price with an EMD-based neural network ensemble learning paradigm. Energy Econ 30:2623-2635. https://doi.org/10.1016/j.eneco.2008.05.003

Publisher's Note Springer Nature remains neutral with regard to jurisdictional claims in published maps and institutional affiliations. 